\title{
Effect of Sacrificial Anodes on Hydrodynamic Coefficients of Jacket Members Subjected to Regular Waves
}

\author{
Ahmad Raziqin, Kurian Velluruzhathil John*, and $\mathrm{Ng}$ Cheng Yee \\ Universiti Teknologi PETRONAS, Civil Engineering Department, 32610 Seri Iskandar, Perak Darul Ridzuan, Malaysia
}

\begin{abstract}
Designing a fixed offshore jacket platform requires the approximation of wave forces acting on jacket members which is influenced by multiple factors such as wave height, wave period, shape and size of the jacket member. An important part of determining wave forces using Morrison's equation is the accurate determination of hydrodynamic coefficients. The presence of sacrificial anodes increases the hydrodynamic coefficient of jacket member and therefore this research focuses on improving the design of fixed offshore platforms by conducting experimental investigation on rigid cylinders in order to obtaining better estimates for hydrodynamic coefficients. Steel members of size 27 and $34 \mathrm{~mm}$ diameters were tested in the wave basin $20 \mathrm{~m}$ x $10 \mathrm{~m} \times 1 \mathrm{~m}$. Different set of regular waves with varying height and frequency were generated. Clean members were fitted with small welded steel bars of fixed length and size along the member simulating sacrificial anodes. The results show that the coefficients obtained were close to the values proposed by PTS and API standards but are generally lower than the suggested value of 2.0 for both $\mathrm{C}_{\mathrm{d}}$ and $\mathrm{C}_{\mathrm{m}}$.
\end{abstract}

\section{INTRODUCTION}

Compared to land structures, offshore structures face various environmental loads, interactions and dynamic responses on top of their static loads which cause the calculation of hydrodynamic forces more complex. Due to the highly indeterministic and un-predictable characteristic of waves, the wave force estimation needs to be done with caution and precision. The wave and current forces acting on these platform members are evaluated using the hydrodynamic drag and inertia coefficients, assumed as constant at all locations on these members for all the wave periods. All these members are covered with increasing thickness of marine growth during operation years and the braces are fitted with sacrificial anodes for corrosion protection. However, due to lack of experimental supporting data, the hydrodynamic coefficients used by the codes are comparatively higher and more conservative. The prediction of accurate values of these coefficients at various depths of water for different wave heights and wave periods will facilitate optimum design for integrity analysis of these platforms, leading to great economy. Hydrodynamic coefficients are found to be influenced by the Reynolds number, the Keulegan-Carpenter $(\mathrm{KC})$ number, and other parameters such as surface roughness, surface area exposed to the waves and current speed [1]. There is no single parameter with which the drag and inertia coefficients may be correlated without the need for other parameters, thus showing the complexity of the determination of hydrodynamic force coefficients [2].

Generally, Morison equation is used to determine the external hydrodynamic force on small structures subjected to wave loadings [3]. This equation assumes that the total in-line hydrodynamic force on a structure consists of semi-empirical values of inertia and drag forces added linearly. The inertia force is developed as the water moving in a wave carry a momentum with it, while the drag force component is caused due to the presence of wake region on the streamside of the cylinder. The total hydrodynamic force on the jacket member can be estimated from Equation 1.

$$
F=\int_{0}^{d} f d s=\int_{0}^{d}\left[\frac{C_{m} \rho \Pi D^{2}}{4} \frac{d u}{d t}+C_{d} \frac{\rho D}{2}\left|u+u_{c}\right|\left(u+u_{c}\right)\right] d s
$$

Where, $\mathrm{d}=$ water depth, $\mathrm{C}_{\mathrm{m}}=$ hydrodynamic coefficient of mass $C_{d}=$ hydrodynamic coefficient of drag, $d s=$ integration is done over the full wetted length of the cylinder, $\rho=$ density of water, $\mathrm{D}=$ pipe diameter, $\mathrm{u}=$ horizontal water particle velocity, $\mathrm{du} / \mathrm{dt}=$ water particle acceleration, and $U_{\mathrm{c}}=$ current velocity. Airy wave theory is used in determining the wave kinematics and the most appropriate combinations of $C_{m}$ and $C_{d}$ corresponding to phase angles that satisfy Equation 1 was selected as the best drag and inertia coefficients for each loading case since both are a function of phase angle $\Theta$.

According to [4] several methods were used in determining the drag and inertia coefficient but it was determined that the Least Square Method produced an overall best. Results by [5] also concluded that Least Square Method produced the best results. It is found that on an average, the wave by wave Weighted Least Squares method gives both the lowest bias and root mean square error.

\footnotetext{
*kurian_john@utp.edu.my
} 


\section{EXPERIMENTAL DETAILS}

The experiments were carried out in the wave basin of Universiti Teknologi PETRONAS (UTP) of size $20 \mathrm{~m}$ by $10 \mathrm{~m}$ with a water depth of $1 \mathrm{~m}$. Various regular waves were ran using 2 different types of cylindrical members. Details for the regular waves used can be seen in Table 1. The specimens used consist of pipe with outer diameters of 27 and $34 \mathrm{~mm}$, both having one clean pipe member and another fitted with anodes. Three wave probes were used to measure the wave elevations during experimentation. The first probe was placed $1.5 \mathrm{~m}$ in front of the model and the other two probes were placed in line at $1.5 \mathrm{~m}$ to the left and right of the model. The anode fittings were $1 \mathrm{~cm} \times 3.5 \mathrm{~cm}$ and spaced $12 \mathrm{~cm}$ from each other centre to centre.

Table 1. Wave combination table

\begin{tabular}{|c|c|}
\hline \multicolumn{2}{|c|}{ Wave Characteristics } \\
\hline Wave Height, (m) & Wave Period, (s) \\
\hline 0.1 & 1 \\
\hline 0.1 & 1.5 \\
\hline 0.1 & 2 \\
\hline 0.1 & 2.5 \\
\hline 0.1 & 3 \\
\hline 0.15 & 1 \\
\hline 0.15 & 1.5 \\
\hline 0.15 & 2 \\
\hline 0.15 & 2.5 \\
\hline 0.15 & 3 \\
\hline 0.2 & 1 \\
\hline 0.2 & 1.5 \\
\hline 0.2 & 2 \\
\hline 0.2 & 2.5 \\
\hline 0.2 & 3 \\
\hline
\end{tabular}

Figure 1 shows the set up used during this experiment. First the clean member was fitted into the coupler which is set up at the bottom of the bridge on the wave tank. The cylinder was mounted vertically using the coupler while the free end was immersed in $1 \mathrm{~m}$ water depth. The model cylinder pipes were made of steel with thickness of $2.5 \mathrm{~mm}$. The total wave force on the cylinder was measured by a wave force sensor located between the coupler and the bridge. The same set up is used for the anode fitted members. Figure 2 shows the anode fitted members used in this experiment.

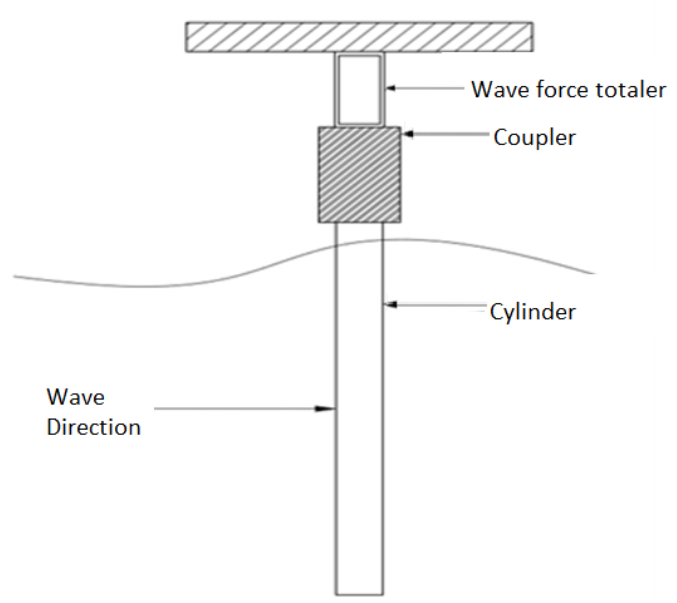

Fig. 1. Model set up in wave basin

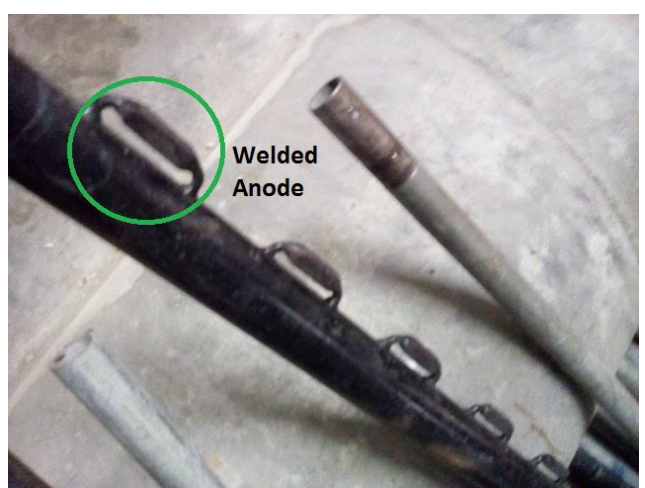

Fig. 2. Anodes fixed onto a steel pipe by welding

Determination of the hydrodynamic coefficients are done by estimation of wave kinematics using Airy Wave Theory and using Least Square Method to provide a good estimation for the hydrodynamic coefficients. Load cells were used to measure the force acting on the cylinder members. The configuration of the load cell is made in such a way that total load acting on the cylinder is read by the load cell in terms of volts, which is further converted in terms of Newton, $\mathrm{N}$ by using appropriate calibration constant. The equation proposed by Morisson gives the Force per unit length but in order to determine the total load acting on cylinder, the Morison equation is integrated from the water surface to the depth up to which structure extends from surface.

The total wave force on the member can be estimated by combining the drag force expressed by Equation 2 with the inertia force in Equation 3.

$$
\begin{aligned}
& F_{D}(t)=\frac{1}{2} C_{D} d \frac{h^{2} \omega^{2}}{4} \frac{\left\{\frac{\sinh (2 \mathrm{kH})}{4}+\frac{k H}{2}\right\}}{k \sinh ^{2}(k H)} \cos (\omega \mathrm{t})|\cos (\omega \mathrm{t})| \\
& F_{l}(t)=-\rho C_{m} \pi \frac{\pi}{4} \mathrm{~d}^{2} \frac{\mathrm{h}}{2 \mathrm{k}} \omega^{2} \sin (\omega \mathrm{t})
\end{aligned}
$$




\section{ANALYSIS}

The methods that can be used for determination of values can be divided into two groups, frequency domain techniques and time domain techniques. Frequency domain techniques use the entire record. The spectra and cross spectra of measured force and particle velocity is determined to estimate the force coefficients. Time domain techniques may also be used for a wave by wave analysis and can be further divided into two-point method and least square approximation. The two points at which the acceleration or, respectively, the velocity is zero, are evaluated. At points of zero acceleration, the corresponding force is purely drag and therefore the drag coefficient can be calculated directly. The same applies for the point in time of zero velocity at which the inertia coefficient can be determined. Due to its simplicity, the coefficients can be obtained with low computational effort. When using the least square approach, an iteration is carried out until values are found for which the force determined with the Morisson equation makes the best fit with the measured force. Hydrodynamic coefficients are varied until the sum of the squares of the difference between measured force $\left(\mathrm{F}_{\mathrm{M}}\right)$ and the estimated Morisson force $\left(\mathrm{F}_{\mathrm{P}}\right)$ is minimized

$$
\varepsilon^{2}=\frac{1}{N} \sum_{\mathrm{t}=1}^{\mathrm{N}}\left(\mathrm{F}_{\mathrm{p}}(\mathrm{t})-\mathrm{F}_{\mathrm{M}}(\mathrm{t})\right)^{2}
$$

with $\varepsilon$ being the squared error and $\mathrm{N}$ the number of time steps. The evaluation can be carried out for one wave or a record of waves. In the least square approach, every data point has an equal influence on the result.

The following figures shows the effect of anodes on the hydrodynamic coefficients with respect to different wave conditions. Figure 3 and Figure 4 illustrates the mass and drag coefficient of member size $27 \mathrm{~mm}$. It can be seen for the most part both mass and drag coefficients were higher in anode fitted member when compared to clean members but the changes were more significant in drag coefficients. The lowest inertia coefficient of anodes fitted members was 1.5 with a maximum of 2.4 while clean members were 1.77 and 2.5 respectively. The drag coefficients for member diameter $27 \mathrm{~mm}$ obtained are depicted in figure 4 show the highest value of drag obtained was 1 with both types of members with a minimum value of 0.1056 and 0.13 for anode and clean member respectively.

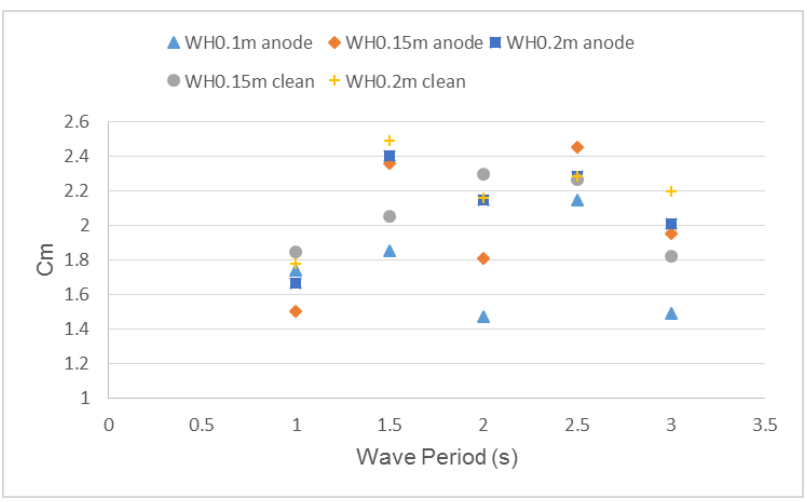

Fig. 3. Mass coefficients for $27 \mathrm{~mm}$ anode fitted cylinder and clean members plotted against different wave periods

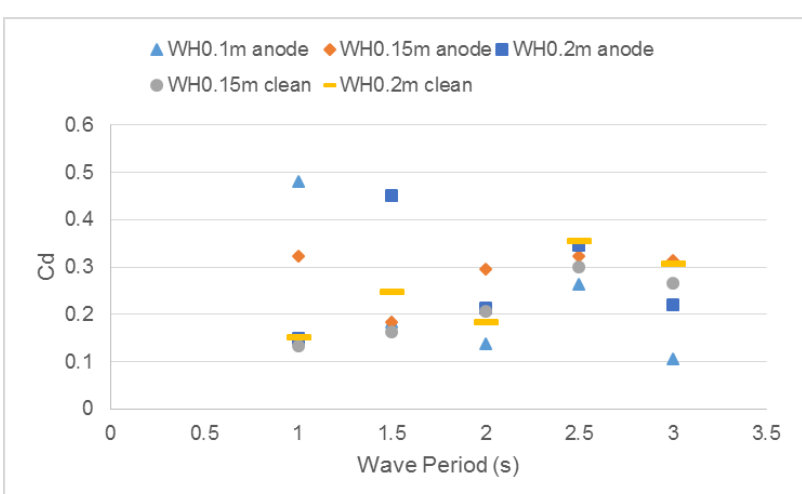

Fig. 4. Drag coefficients for $27 \mathrm{~mm}$ anode fitted cylinder and clean members plotted against different wave periods

Figure 5 and Figure 6 that shows the mass and drag coefficients of anode fitted members and clean members of size $34 \mathrm{~mm}$. It can be seen that the presence of anodes increases the mass coefficient values for most wave periods used. The lowest coefficient obtained was 1.4076 for anode and 1.56 for clean member with a peak of 2.46 and 2.4 respectively. Results presented in Figure 6 show similar trends in which the presence of anodes increased the drag coefficient. The highest drag coefficient obtained was 0.43 for anodes and 0.35 for clean members wiles the minimum values obtained are 0.113 and 0.035 respectively.

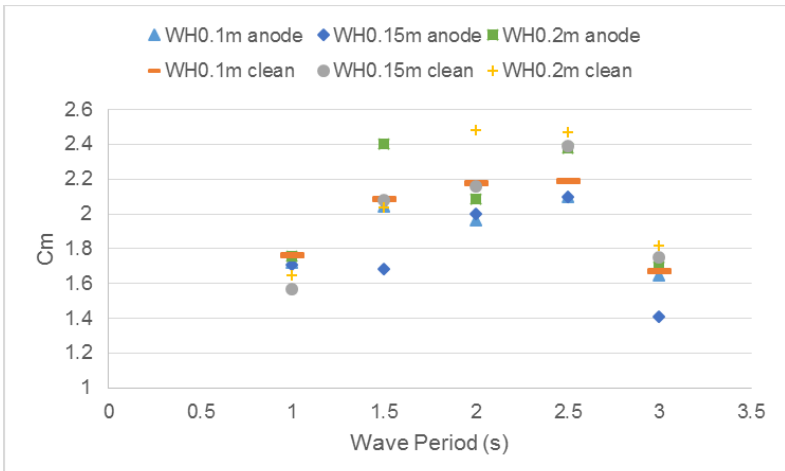

Fig. 5. Mass coefficients for $34 \mathrm{~mm}$ anode fitted cylinder and clean members plotted against different wave periods

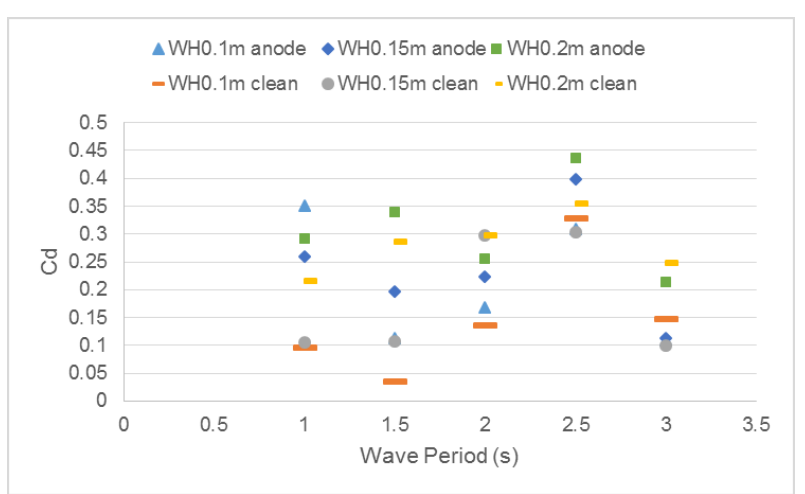

Fig. 6. Drag coefficients for $34 \mathrm{~mm}$ anode fitted cylinder and clean members plotted against different wave periods

Figure 7 and 8 compare the mass and drag coefficient for clean member of size $27 \mathrm{~mm}$ and $34 \mathrm{~m}$. The two 
different pipe diameter show a general trend of increase in both mass and drag coefficient as pipe diameter increases.

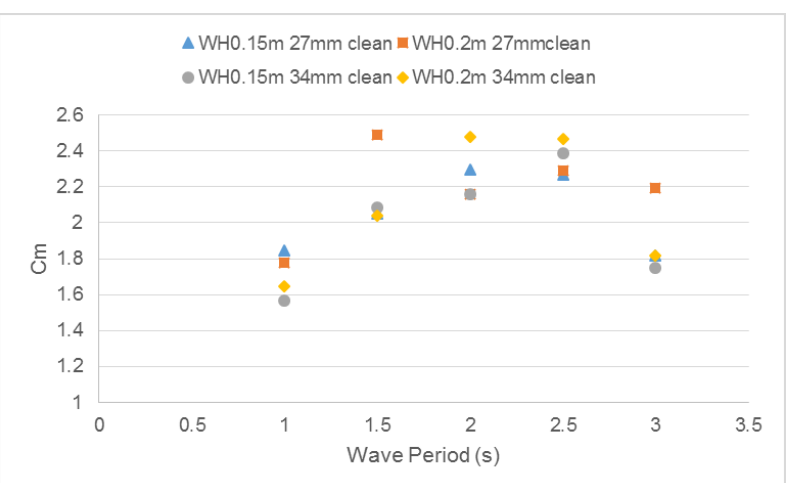

Fig. 7. Mass coefficients for $27 \mathrm{~mm}$ and $34 \mathrm{~mm}$ clean members plotted against different wave periods

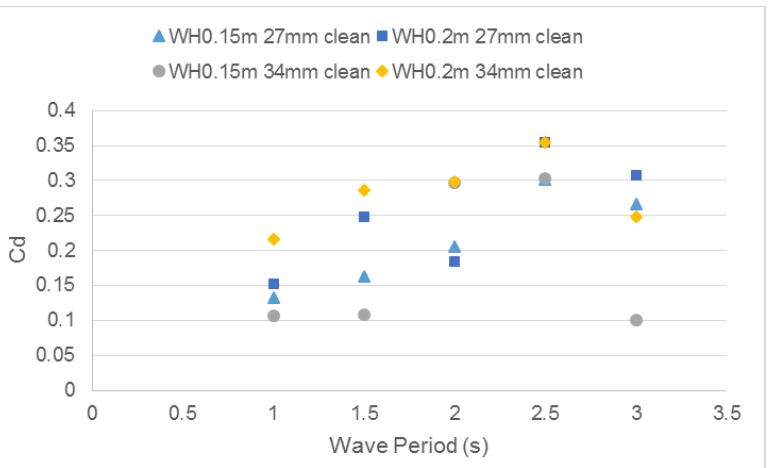

Fig. 8. Drag coefficients for $27 \mathrm{~mm}$ and $34 \mathrm{~mm}$ clean members plotted against different wave periods.

From the results obtained, it can be seen that anode fittings have increased the overall of both drag coefficients and inertia coefficient in both $27 \mathrm{~mm}$ and $34 \mathrm{~mm}$ pipe member but has a higher effect on drag compared to inertia coefficient. Although the mass coefficient obtained in this experiment was higher than recommended values in PTS, the total force produced by the combination of drag and inertia were the same. Results obtained from this experiment are in agreement with values recommended by [6] but a large part of the findings suggest that the standard hydrodynamic coefficients for anode fitted members used in designing were still conservative.

\section{CONCLUSION}

The results of the experiment show that the fitting of anodes onto a clean member generally increases the hydrodynamic coefficient of the cylinder. The overall effect of anode fittings on inertia coefficients were smaller when compared to drag coefficient. The drag and inertia coefficients obtained are in agreement with values suggested by PTS. However, a large portion of the results suggests that the standard values for anode fitted members are conservative because the force measured was less than the combination of $\mathrm{Cm}=2.0$ and $\mathrm{Cd}=2.0$.

\section{Acknowledgement}

This research was funded by the Fundamental Research Grant Scheme (FRGS 2014-2) under the Ministry of Higher Education (MOHE).

\section{REFERENCES}

[1] Chakrabati, S.K., (1991). Wave force on offshore structures. Handbook of Coastal and Ocean engineering, 2, pp.1-54.

[2] Shafieefar, M. and Massie, W.W., 2001. In-Line Force from Combined Wave and Current Flow on Oscillating Cylinders. International Journal of Offshore and Polar Engineering, 11(02).

[3] Morison, J.R., Johnson, J.W. and Schaaf, S.A., (1950). The force exerted by surface waves on piles. Journal of Petroleum Technology, 2(5), pp.149-154.

[4] Isaacson, M., Subbiah, K. and Baldwin, J., 1991, January. Force coefficient estimation from random wave data. The First International Offshore and Polar Engineering Conference. International Society of Offshore and Polar Engineers.

[5] Naghipour, M., (2001). Estimation of hydrodynamic force on rough circular cylinders in random waves and currents. International Journal of Engineering, 14(1), pp.25-34.

[6] PTS, Petronas Technical Standards, Design of Fixed Offshore Structures. (2012).

[7] Li, Y. C., \& Ming, H. (1995). The In-Line Wave Forces on Small Square Cylinder. Proc. Of the Fifth International Offshore and Polar Engineering Conf. City: The Hague, The Netherlands, pp. 289-296.

[8] Borgman, L.E., (1958). Computation of the ocean-wave forces on inclined cylinders. Eos, Transactions American Geo-physical Union, 39(5), pp.885-888. 